\title{
MICROCÁPSULAS DE ALGINATO DE CÁLCIO E ÓLEO VEGETAL PELA TÉCNICA DE GELIFICAÇÃO IÔNICA: UM ESTUDO DA CAPACIDADE DE ENCAPSULAMENTO E APLICAÇÃO DERMATOLÓGICA
}

\author{
MICROCAPSULES OF CALCIUM ALGINATE AND VEGETABLE OIL BY IONIC \\ GELATION: A STUDY OF ENCAPSULATION CAPACITY AND SKIN APLICATION
}

\author{
PASQUALIM, P. ${ }^{1}$; CULPI, T.A. ${ }^{1}$; KAMINSKI, G.A.T1; FIN, M.T. 1; SASSO, D.G.B. 1; \\ COSTA, C.K. ${ }^{2}$; MIGUEL, M.D. ${ }^{2}$; FUJIWARA, G.M. ${ }^{3}$; RODRIGUES, B.H. ${ }^{4}$; ZANIN, \\ S.M.W. ${ }^{2}$
}

${ }^{1}$ Acadêmicos do Curso de Farmácia, Iniciação Científica da Universidade Federal do Paraná.

${ }^{2}$ Professoras do Curso de Farmácia da Universidade Federal do Paraná.

${ }^{3}$ Aluna do Curso de Pós-Graduação em Ciências Farmacêuticas da Universidade Federal do Paraná.

${ }^{4}$ FMC Biopolymer Química do Brasil Ltda.

1,2,3 Laboratório de Farmacotécnica, Departamento de Ciências Farmacêuticas, Centro de Ciências da Saúde, Universidade Federal do Paraná, Campus Jardim Botânico, Curitiba, Paraná, Brasil. e-mail sandrazanin@ufpr.br

\section{RESUMO}

REC: 11/09 AC; 120/09

\begin{abstract}
Na microtecnologia, em se tratando de produtos cosméticos e farmacêuticos, a substância ativa, ao invés de ser adicionada diretamente no veículo em forma livre, é encapsulada em vesículas micrométricas, denominadas microcápsulas. Essas estruturas são sistemas de liberação controlada de fármacos, formadas por uma porção externa, um fino filme polimérico responsável pelo revestimento, suporte e proteção; e por uma porção interna, constituída por pequenas quantidades da substância farmacologicamente ativa. As vantagens da utilização desse sistema incluem proteger o ativo da degradação por diminuir seu contato com o restante da formulação; oferecer maior resistência, estabilidade e proteção contra oxidação e fotodegradação; mascarar sabores e odores desagradáveis do princípio ativo; aumentar seu tempo de ação e separar incompatibilidades. Assim, o objetivo desse trabalho foi analisar o desenvolvimento de micropartículas de alginato de sódio pela metodologia de gelificação iônica, tomando como ponto de partida a determinação da capacidade de encapsulamento do óleo vegetal de semente de uva, seleção da melhor faixa de trabalho e posterior aplicação da metodologia em um produto cosmético ou farmacológico. Os resultados demonstraram a formação das microcápsulas de alginato de cálcio contendo óleo em todas as concentrações testadas dos reagentes, sendo que, nas menores concentrações dos mesmos, as microcápsulas não suportaram mais do que $12 \%$ de óleo e se apresentaram mal estruturadas. Nas demais concentrações as partículas mostraram-se brilhantes e com espessura de parede desejável para aplicação dérmica. Quanto ao microencapsulamento de mentol e cânfora, o mesmo ocorreu de maneira desejável, sendo incorporado em forma farmacêutica de aplicação dermatológica.
\end{abstract}

Palavras-chave: Microencapsulamento, Gelificação lônica, Alginato de sódio.

\begin{abstract}
Microtechnology science, applied on cosmetic and pharmaceutical products, the active ingredient, rather than being added directly into the vehicle, is encapsulated in micrometrics vesicles, called microcapsules. These structures are drugs controlled release systems formed by an external portion, a thin polymer film responsible for coating, support and protection; and
\end{abstract}


an internal portion, constituted of small amounts of the pharmacologically active substance. The advantages of using this system include protecting the active ingredient of degradation by reducing oxidation and photodegradation; increase strength, stability and protection; to mask unpleasant smells and tastes of the active ingredient and avoiding incompatibilities. Therefore, the objective of this study was to analyze the development of microparticles of sodium alginate by ionic gelation technique in order to establish the high oil encapsulation capacity and methodology application in cosmetic or pharmacological products. The results showed that at lower concentration of ingredients, the microcapsules did not support more than $12 \%$ of oil and presented low homogeneity structure. In other concentrations, microcapsules appeared bright surface and wall thickness, desirable for dermatological application. Menthol and camphor microencapsulation presented properly applied uses.

Keywords: Microencapsulation, lonic gelation, Sodium alginate

\section{INTRODUÇÃO}

Micropartículas são sistemas poliméricos sólidos e esféricos de tamanho variando entre 1 e $1000 \mu \mathrm{m}$. São subdivididas em microcápsulas, microesferas e microesferas lipídicas (SILVA et al., 2003).

As microcápsulas são sistemas onde é possível diferenciar o núcleo, que contém a substância ativa, do invólucro, constituído por polímeros de espessuras variáveis. Podem ser denominadas mononucleares ou polinucleares, pela divisão ou não do núcleo no interior da partícula revestida (SILVA et al., 2003). Visto que a substância ativa encontra-se dissolvida, são consideradas um sistema reservatório (DURÁN et al., 2002).

Já as microesferas são um sistema matricial onde o fármaco encontrase uniformemente disperso e/ou dissolvido em uma rede polimérica. Podem ser denominadas homogêneas ou heterogêneas, sendo que no primeiro caso a substância ativa encontra-se no seu estado molecular (dissolvido) e no segundo na forma de partículas (suspenso) (SILVA et al., 2003). Trata-se de um sistema monolítico, onde não é possível identificar um núcleo diferenciado (DURÁN et al., 2002).

A seleção do agente encapsulante depende do método utilizado para formar as microcápsulas, do tipo de aplicação do produto e ainda da forma como ele agirá. A liberação da substância ativa pode se dar por estímulo mecânico (rompimento das microcápsulas por pressão) ou outros como variação de temperatura ou pH no meio onde estão as micropartículas (RÊ, 2000).

O polímero biodegradável escolhido, o alginato de sódio, apresenta-se como um pó colorido branco pálido ou marrom amarelado, inodoro e insípido. Consiste principalmente do sal sódico do ácido algínico, ou seja, uma mistura de ácidos poliurônicos composto de resíduos de ácido D-manurônico e ácido L-gulurônico (ROWE et al., 2009). Tem sido bastante aplicado na microencapsulamento de drogas em contraste com as técnicas de microencapsulamento convencional que utilizam sistemas de solventes orgânicos (ROWE et al., 2009).

Quanto aos ativos utilizados, o mentol é uma mistura racêmica de partes iguais dos isômeros (1R, 2S, 5R) e (1S, 2R, 5S). Apresenta-se na forma de pó cristalino ou cristais brilhantes prismáticos ou aciculares, incolor e com odor forte e característico. 
É amplamente utilizado na indústria farmacêutica, produtos alimentícios e produtos de higiene como um agente de aroma ou potencializador de odor. Além disso, exerce uma ação refrescante, a qual é explorada em muitas preparações tópicas por interagir diretamente com os receptores de frio do corpo. Fisiologicamente, quando aplicado sobre a pele, o mentol dilata os vasos sanguíneos, causando a sensação de frieza, seguido de um efeito analgésico. Em produtos farmacêuticos a concentração usual desse princípio ativo varia de $0,003 \%$ a $10,0 \%$, e em produtos cosméticos varia de 0,1\% a 2,0\% (ROWE et al., 2009).

Já a cânfora é um terpenóide com fórmula estrutural $\mathrm{C}_{10} \mathrm{H}_{16}$ encontrado na seiva da planta Cinnamomum camphora apresentando-se como um pó branco, cristalino, com odor forte e característico (CAMPHOR, 2010). É usada como um medicamento rubefaciente, ou seja, quando aplicado sobre a pele produz uma vasodilatação local nos tecidos, o que se manifesta com a vermelhidão da pele, aumentando a circulação sangüínea e a nutrição dos tecidos afetados. A cânfora é utilizada em preparações de pomadas, linimentos, loções, cremes, tendo como concentração usual $0,5 \%$ a 2,0\% (CÂNFORA, 2003; CÂNFORA, 2010). Suas principais indicações terapêuticas são antiséptica, estimulante, antireumática, parasiticida, anti-nevrálgica, revulsiva, anestésico local, anti-térmica, anti-diarréica, anti-helmíntica, moderadora das secreções sudoral e láctea (CAMPHOR, 2010).

Em relação ao método utilizado, a gelificação iônica é simples e de baixo custo, ocorre quando uma solução polimérica contendo o material de núcleo é gotejada sobre uma solução iônica em concentrações adequadas, podendo-se obter razoáveis níveis de recheio e capsulas de diferentes fórmulas e tamanhos (CORREA et al., 2005).

\section{MATERIAL E MÉTODOS}

\subsection{Microcápsulas de Alginato de Sódio}

A técnica de microencapsulamento com alginato de sódio foi desenvolvida segundo o artigo de Calero et al. (2008) com as seguintes alterações: uma solução de alginato de sódio U.S. (FMC-BioPolymer) foi preparada por meio da hidratação do pó (quantidade definida em gramas) em $100 \mathrm{~g}$ de água deionizada e posterior aquecimento para a completa dissolução do mesmo até a temperatura de $60^{\circ} \mathrm{C} \pm 5^{\circ} \mathrm{C}$ (Banho Maria Quimis). A essa solução adicionou-se óleo de semente de uva (Purifarma) corado com corante lipofílico "fat red" (7B F-100, Sigma Chemical) sob agitação em Ultra-Turrax (15000rpm durante 1 minuto). A solução de cloreto de cálcio (90-93\%, e-Merck AG Darmstadt) foi preparada por meio da solubilização do pó (quantidade definida em gramas) em $100 \mathrm{~g}$ de água deionizada em agitação magnética (agitador Mag-Mix, Precision Scientific, cat. n. 65904, série n. 4-aa-6).

Para a formação das microcápsulas, a solução de alginato+óleo foi gotejada, com auxílio de seringa e agulha (seringa $10 \mathrm{~mL}$ BD e agulha $30 \times 7 \mathrm{~mm}$ ), sobre a solução de cloreto de cálcio em agitação magnética. Após isso, foram separadas da solução de cloreto com auxílio de uma peneira e lavadas para retirar o excesso do sal com aproximadamente $800 \mathrm{~mL}$ de água deionizada. A seguir, foram colocadas em placa de Petri limpa e seca para as análises. 
As análises de microscopia óptica foram realizadas em aumento de $10 \mathrm{x}$ (microscópio studar lab, produzido por Metrimpax Hungary em cooperação com PZOlabimex) e fotografadas com máquinas digitais Panasonic Lumix 5.0 mega pixels, 6x zoom óptico DMC-LZ2 e Sony Cyber Shot 6.1 mega pixels, 3x zoom óptico.

Os reagentes foram pesados em balanças Radwag as 220/c/2 (Radwag Wagi Elektroniczine, n. 2481 20/09) para aqueles de alto peso e balança eletrônica de precisão Gehaka BG 2000 (n. 907361) para aqueles de menor peso.

\subsubsection{Capacidade de Encapsulamento}

O primeiro experimento realizado objetivou encontrar as melhores concentrações de alginato de sódio e cloreto de cálcio para aplicação da técnica de microencapsulamento, tendo como parâmetros a uniformidade de tamanho e forma bem como a espessura e resistência da parede da microcápsula, por meio de análise visual. Assim, foram realizados experimentos com concentrações crescentes de soluções de alginato de sódio e cloreto de cálcio, sendo que as concentrações escolhidas em ambos os compostos foram $0,5 \%$ e $1,0 \%$. Nesses casos, as microcápsulas apresentaram melhor desempenho quanto aos parâmetros analisados, ou seja, possuíam boa homogeneidade de tamanho inter e intra-experimentos, forma circular bem como uma parede definida e medianamente resistente ao toque.

Dessa forma, para o experimento de capacidade de encapsulamento de óleo de origem vegetal, as microcápsulas de alginato foram produzidas conforme descrito anteriormente, fazendo-se uso das associações descritas nos fluxogramas a seguir.

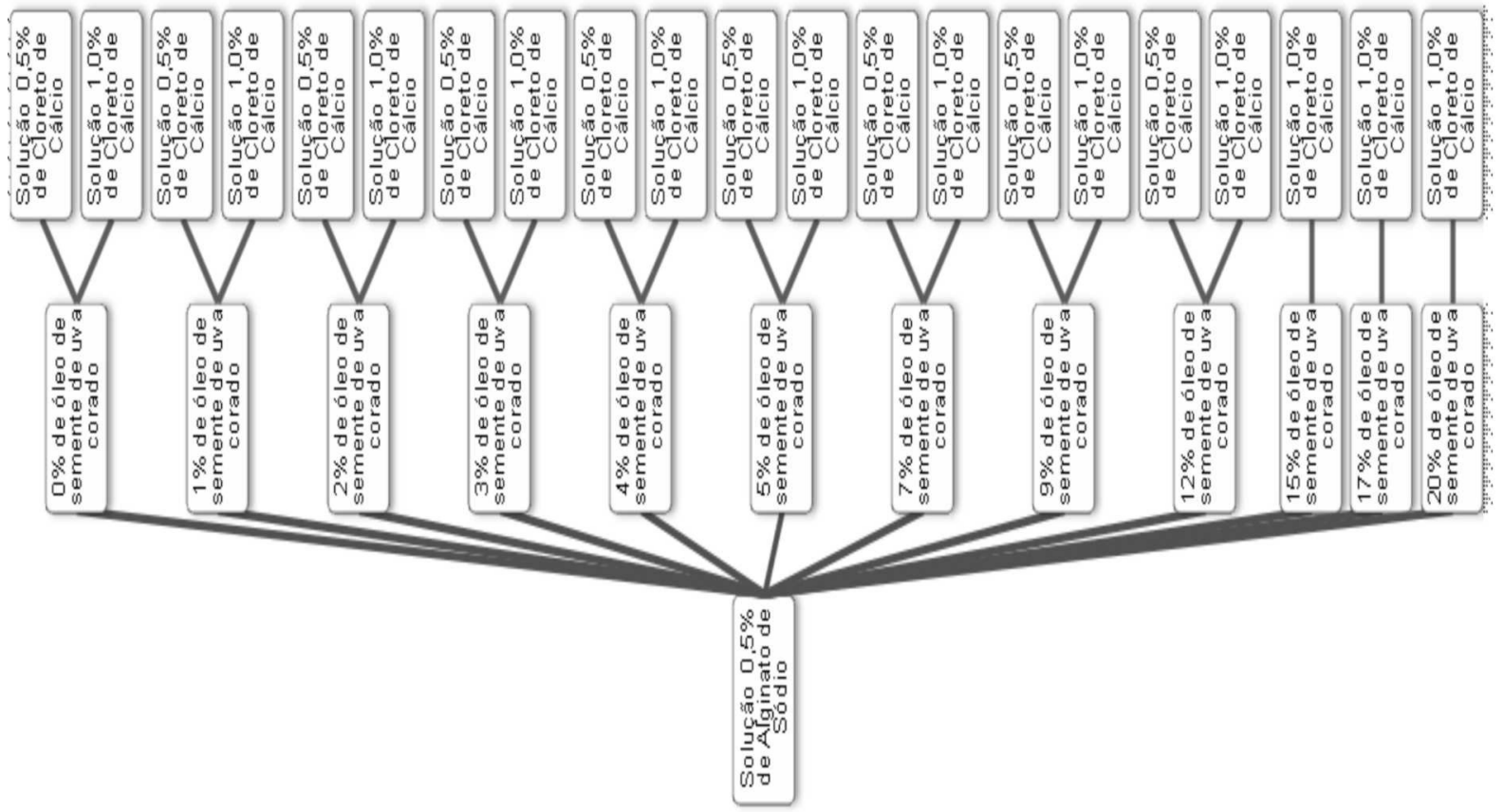

FLUXOGRAMA 1 - PREPARO DE MICROCÁPSULAS DE ALGINATO DE SÓDIO 0,5\% COM CONCENTRAÇÕES CRESCENTES DE ÓLEO DE SEMENTE DE UVA CORADO EM SOLUÇÕES DE CLORETO DE CÁLCIO 0,5\% E 1,0\%

FONTE: O autor (2010) 


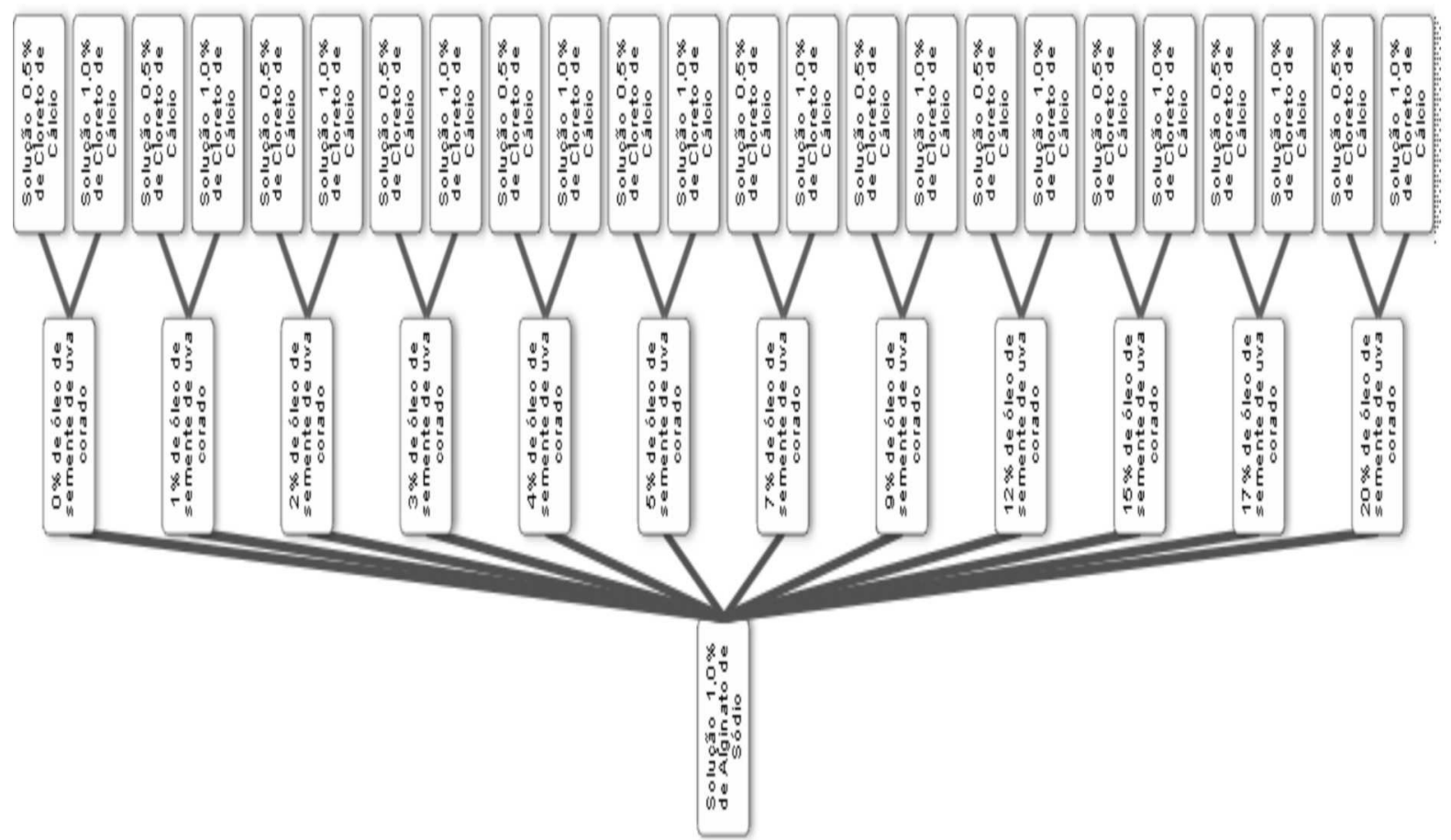

FLUXOGRAMA 2 - PREPARO DE MICROCÁPSULAS DE ALGINATO DE SÓDIO 1,0\% COM CONCENTRAÇÕES CRESCENTES DE ÓLEO DE SEMENTE DE UVA CORADO EM SOLUÇÕES DE CLORETO DE CÁLCIO 0,5\% E 1,0\%.

FONTE: O autor (2010)

2.1.2 Microencapsulamento de Cânfora e Mentol

Tomando como base a técnica de microencapsulamento definida no item 4.1, incorporou-se mentol (Mentol Cristal Farm, Galena Química e Farmacêutica Ltda, origem Brasil) e cânfora no óleo utilizado como material de núcleo, para aplicação farmacológica. O óleo de semente de uva foi utilizado como veículo, pois os ativos mostraram-se altamente solúveis nesse. As porcentagens foram: mentol e cânfora $0,5 \%$, alginato de sódio $0,5 \%$, cloreto de cálcio $1,0 \%$ e óleo de semente de uva $12 \%$. A solução de alginato de sódio foi resfriada a $40^{\circ} \mathrm{C}$ antes da adição do óleo contendo os ativos a fim de evitar a volatilização desses compostos. Depois de formadas, as microcápsulas foram lavadas conforme metodologia e incorporadas na porcentagem de $10 \%$ em um gel de natrosol a $1 \%$.

Uma variação dessa técnica envolveu a utilização de corante azul hidrofílico (corante azul abl-9, Brasquim Especialidades Cosméticas) para corar a solução de alginato e óleo de semente de uva sem corante. Além disso, utilizou-se uma seringa menor (KDL 13×4,5mm) a fim de obter partículas de menor tamanho. Essas também foram incorporadas na porcentagem de $10 \%$ em gel de Natrosol a $1 \%$.

\section{RESULTADOS}

\subsection{CAPACIDADE DE MICROENCAPSULAMENTO}

3.1.1 Microcápsulas de alginato de sódio 0,5\% 


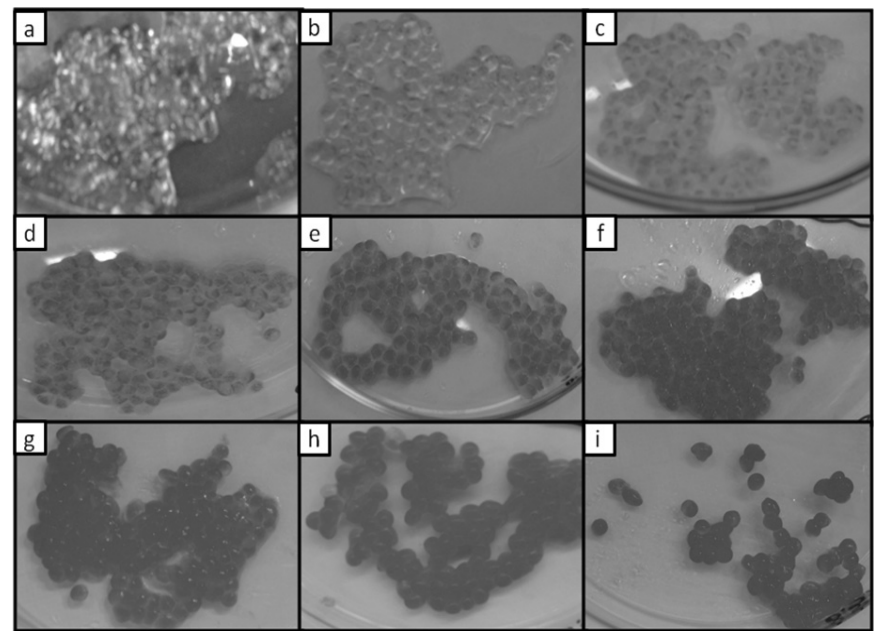

FIGURA 12 - MICROCÁPSULAS DE ALGINATO DE SÓDIO 0,5\% E CLORETO DE CÁLCIO 0,5\% CONTENDO CONCENTRAÇÕES CRESCENTES DE ÓLEO DE SEMENTE DE UVA CORADO, VISÃO AO OLHO NU. As microcápsulas foram formadas conforme descrito no item 4.1 de Material e Métodos. As concentrações crescentes de óleo utilizadas foram: $a-0 \% ; b-1 \% ; c-2 \% ; d-3 \% ; e-4 \% ; f-5 \%$; $\mathrm{g}-7 \%$; $\mathrm{h}-9 \% ; \mathrm{i}-12$.

FONTE: O autor (2010)

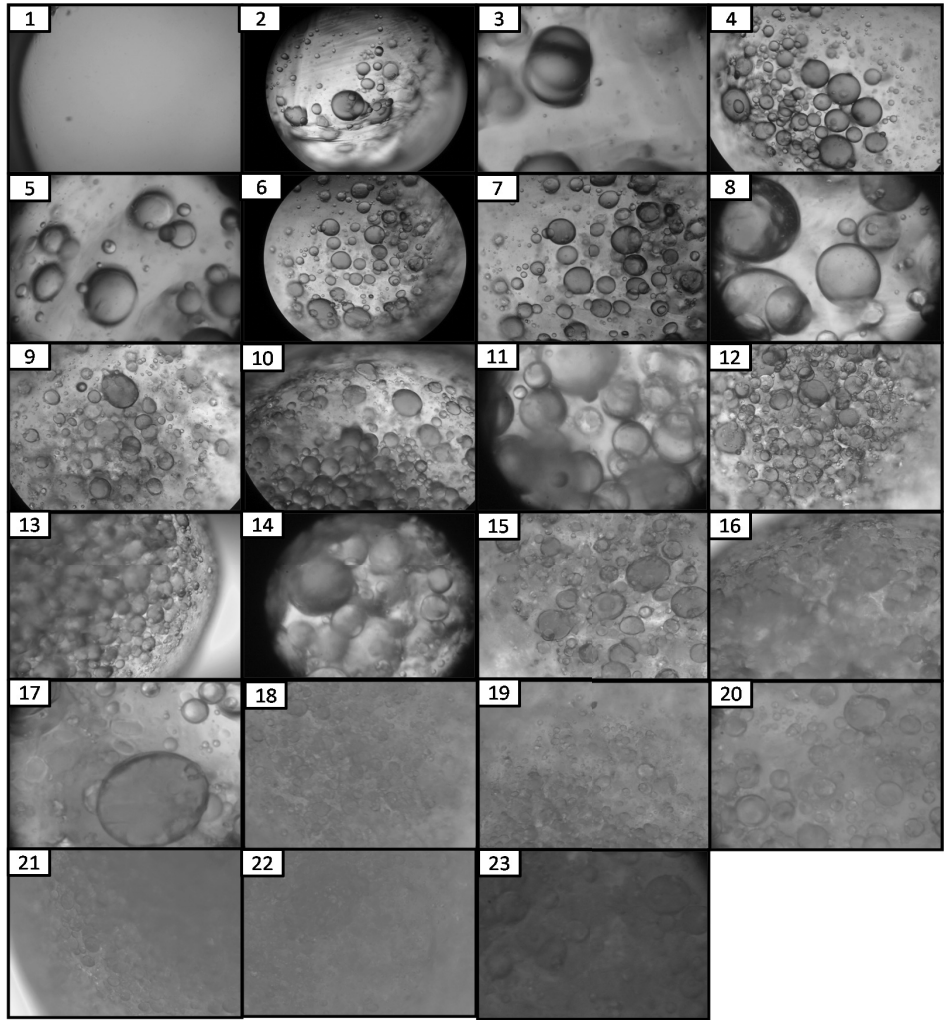

FIGURA 13 - MICROCÁPSULAS DE ALGINATO DE SÓDIO 0,5\% E CLORETO DE CÁLCIO 0,5\% CONTENDO CONCENTRAÇÕES CRESCENTES DE ÓLEO DE SEMENTE DE UVA CORADO, VISÃO AO MICROSCÓPIO ÓPTICO. As microcápsulas foram formadas conforme descrito no item 4.1 de Material e Métodos. As concentrações crescentes de óleo utilizadas foram: $1-0 \%$; 2 e $3-1 \%$; 4 e $5-2 \%$; 6 , 7 e $8-3 \%$; 9 , 10 e $11-4 \%$; 12 , 13 e $14-5 \%$; 15 , 16 e $17-7 \%$; 18,19 e $20-9 \%$; 21 , 22 e $23-12 \%$. Todas as fotografias foram retiradas com aumento de $10 \mathrm{x}$ no microscópio óptico, sendo que nas fotos 
$3,5,8,11,14,17,20$ e 23 utilizou-se o zoom óptico da máquina digital de aproximadamente 3x para melhor visualização das partículas de óleo.

FONTE: O autor (2010)

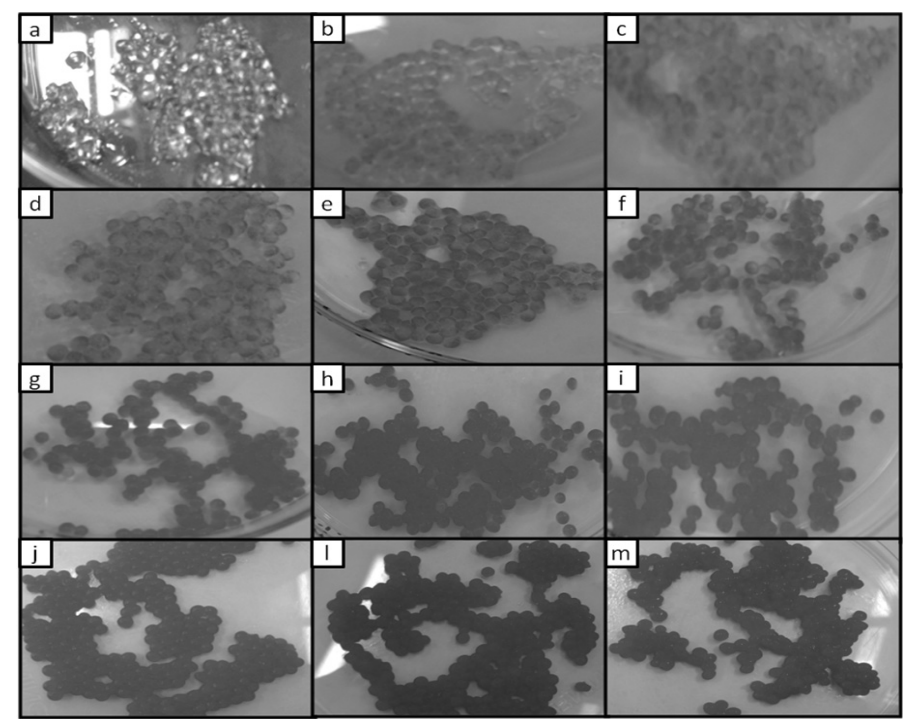

FIGURA 14 - MICROCÁPSULAS DE ALGINATO DE SÓDIO 0,5\% E CLORETO DE CÁLCIO 1,0\% CONTENDO CONCENTRAÇÕES CRESCENTES DE ÓLEO DE SEMENTE DE UVA CORADO, VISÃO AO OLHO NU. As microcápsulas foram formadas conforme descrito no item 4.1 de Material e Métodos. As concentrações crescentes de óleo foram: $a-0 \% ; b-1 \%$; $-2 \%$; $d-3 \%$; e - 4\%; f $-5 \%$; $g-7 \%$; $\mathrm{h}-9 \% ; \mathrm{i}-12 ; \mathrm{j}-15 \%$; l-17\%; $\mathrm{m}-20 \%$.

FONTE: O autor (2010) 


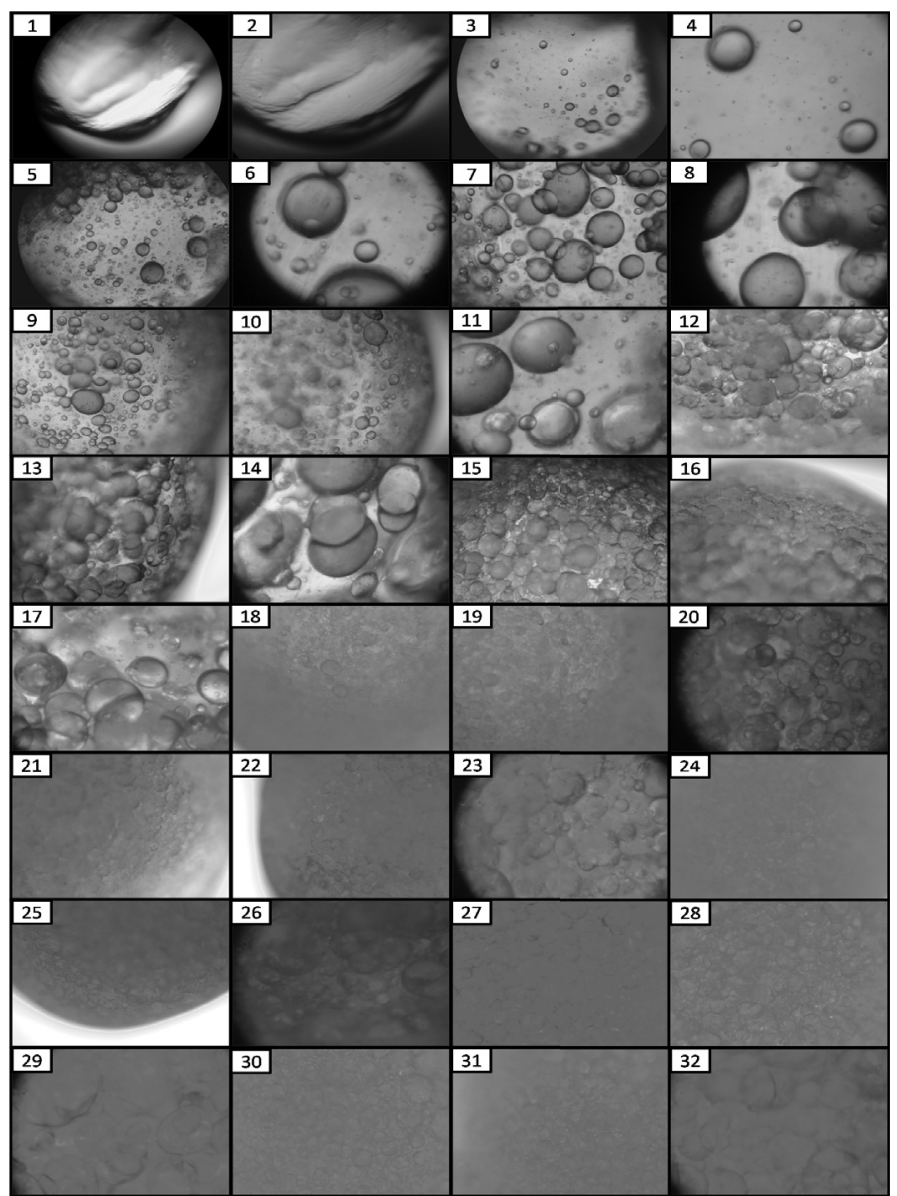

FIGURA 15 - MICROCÁPSULAS DE ALGINATO DE SÓDIO 0,5\% E CLORETO DE CÁLCIO 1,0\% CONTENDO CONCENTRAÇÕES CRESCENTES DE ÓLEO DE SEMENTE DE UVA CORADO, VISÃO AO MICROSCÓPIO ÓPTICO. As microcápsulas foram formadas conforme descrito no item 4.1 de Material e Métodos. As concentrações crescentes de óleo foram: 1 e $2-0 \%$; 3 e $4-1 \%$; 5 e $6-2 \%$; 7 e 8 $3 \% ; 9,10$ e $11-4 \% ; 12$, 13 e $14-5 \% ; 15$, 16 e $17-7 \% ; 18,19$ e $20-9 \% ; 21,22$ e $23-12 \% ; 24,25$ e $26-15 \% ; 27$, 28 e $29-17 \%$; 30 , 31 e $32-20 \%$. Todas as fotografias foram retiradas com aumento de 10x no microscópio óptico, sendo que nas fotos $4,6,8,11,14,17,20,23,26,29$ e 32 utilizou-se o zoom óptico da máquina digital de aproximadamente $3 x$ para melhor visualização das partículas de óleo. FONTE: O autor (2010)

3.1.2 Microcápsulas de alginato de sódio 1,0\% 


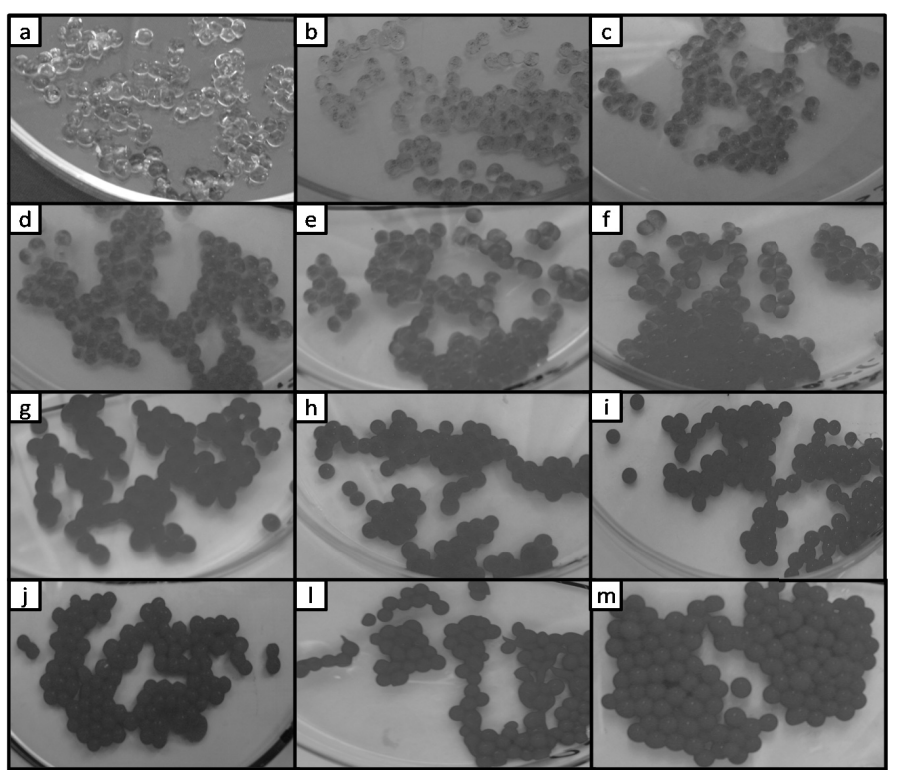

FIGURA 16 - MICROCÁPSULAS DE ALGINATO DE SÓDIO 1,0\% E CLORETO DE CÁLCIO 0,5\% CONTENDO CONCENTRAÇÕES CRESCENTES DE ÓLEO DE SEMENTE DE UVA CORADO, AO OLHO NU. As microcápsulas foram formadas conforme descrito no item 4.1 de Material e Métodos. As concentrações crescentes de óleo foram: $a-0 \% ; b-1 \%$; $-2 \%$; $d-3 \%$; e $-4 \% ; f-5 \% ; g-7 \% ; h-$ $9 \% ; \mathrm{i}-12 ; \mathrm{j}-15 \% ; \mathrm{l}-17 \% ; \mathrm{m}-20 \%$.

FONTE: O autor (2010)

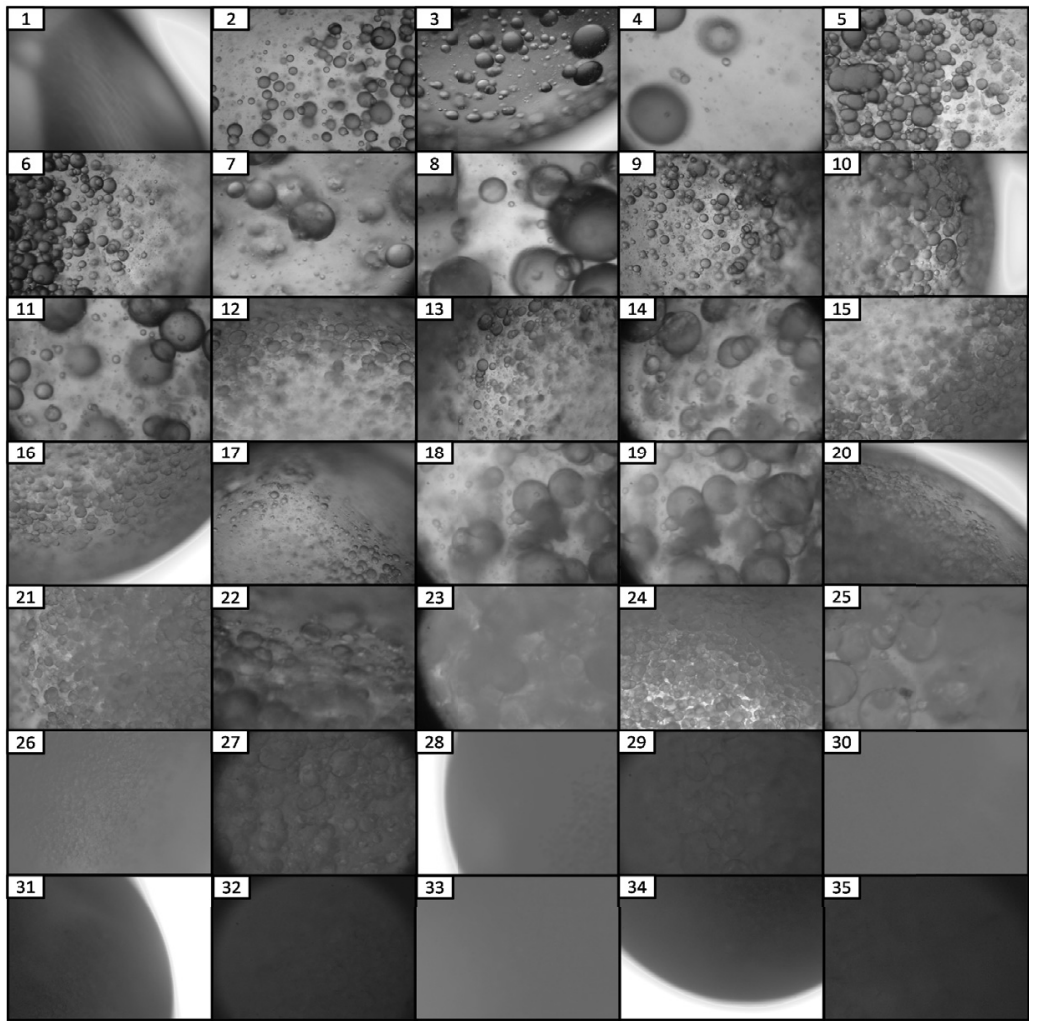

FIGURA 17 - MICROCÁPSULAS DE ALGINATO DE SÓDIO 1,0\% E CLORETO DE CÁLCIO 0,5\% CONTENDO CONCENTRAÇÕES CRESCENTES DE ÓLEO DE SEMENTE DE UVA CORADO, VISÃO AO MICROSCÓPIO ÓPTICO. As microcápsulas foram formadas conforme descrito no item 4.1 de Material 
e Métodos. As concentrações crescentes de óleo foram: 1 - 0\%; 2, 3 e $4-1 \% ; 5,6,7$ e $8-2 \%$; 9 , 10 e $11-3 \%$; 12 , 13 e $14-4 \%$; 15, 16, 17, 18 e 19 g- 5\%; 20, 21, 22 e $23-7 \%$; 24 e $25-9 \%$; 26 e 27 - 12; 28 e $29-15 \%$; 30, 31 e $32-17 \%$; 33, 34 e $35-20 \%$. Todas as fotografias foram retiradas com aumento de 10x no microscópio óptico, sendo que nas fotos $4,7,8,11,14,18,19,22,23,25,27,29$, 32 e 35 utilizou-se o zoom óptico da máquina digital de aproximadamente $3 x$ para melhor visualização das partículas de óleo.

FONTE: O autor (2010)

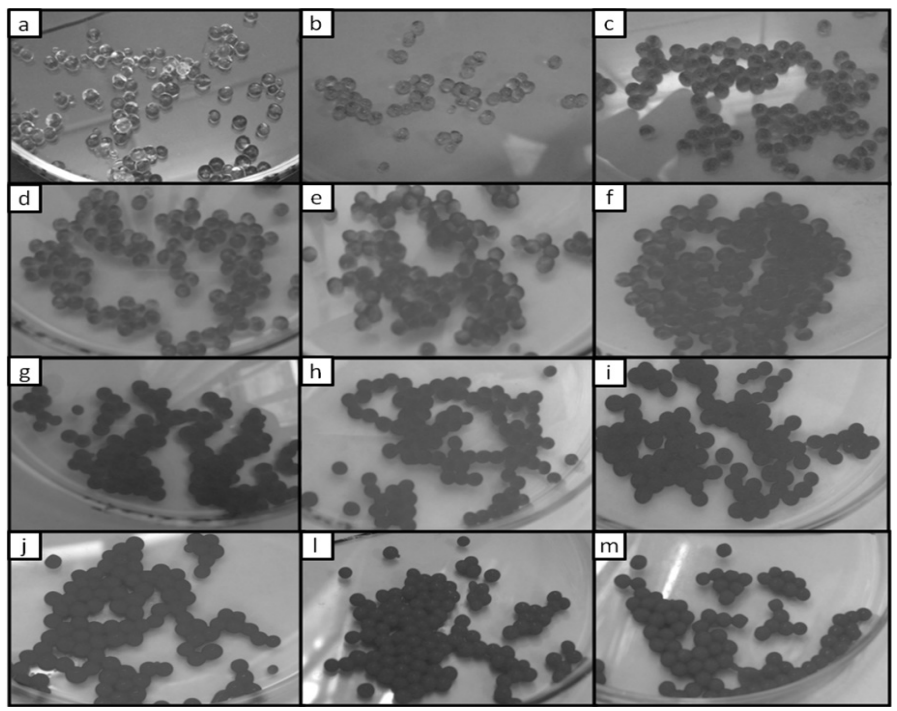

FIGURA 18 - MICROCÁPSULAS DE ALGINATO DE SÓDIO 1,0\% E CLORETO DE CÁLCIO 1,0\% CONTENDO CONCENTRAÇÕES CRESCENTES DE ÓLEO DE SEMENTE DE UVA CORADO, VISÃO AO OLHO NU. As microcápsulas foram formadas conforme descrito no item 4.1 de Material e Métodos. As concentrações crescentes de óleo foram: $a-0 \% ; b-1 \%$; $-2 \%$; $d-3 \%$; e $-4 \% ; f-5 \% ; g-7 \%$; h - 9\%; i - 12; j- 15\%; l-17\%; m - 20\%.

FONTE: O autor (2010) 


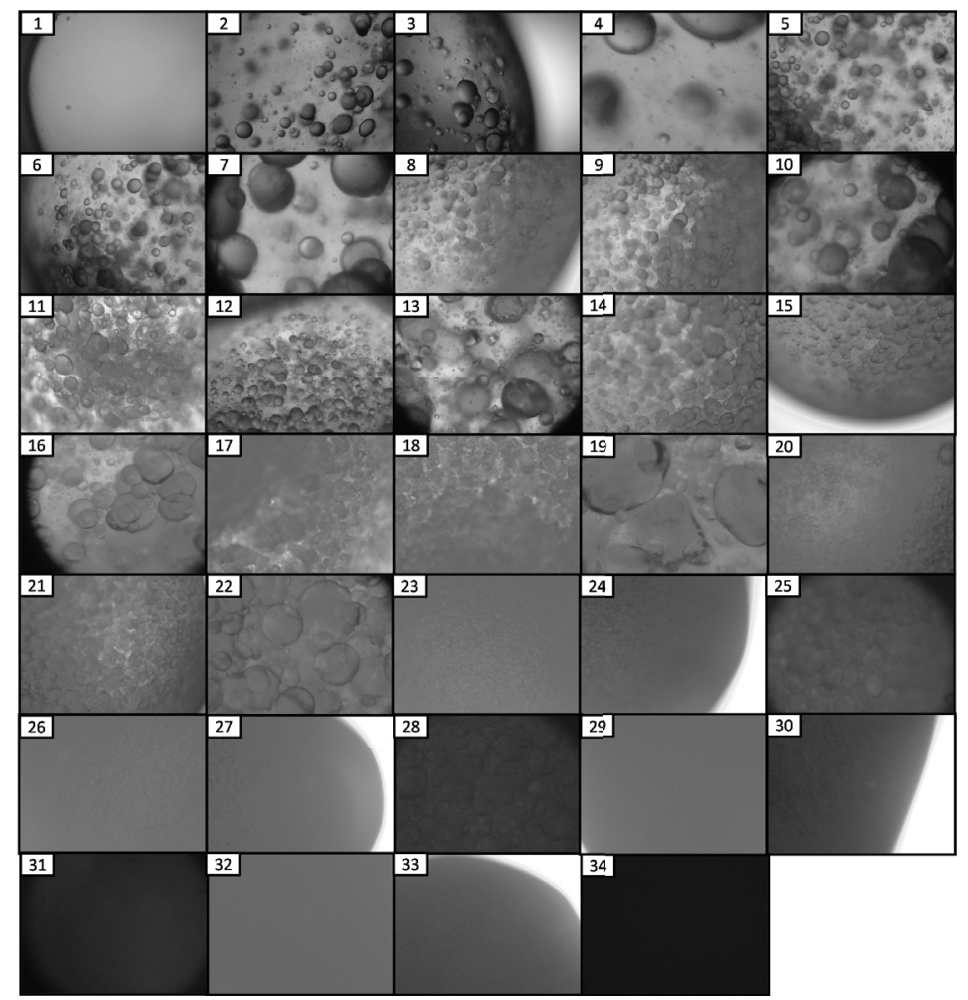

FIGURA 19 - MICROCÁPSULAS DE ALGINATO DE SÓDIO 1,0\% E CLORETO DE CÁLCIO 1,0\% CONTENDO CONCENTRAÇÕES CRESCENTES DE ÓLEO DE SEMENTE DE UVA CORADO, VISÃO AO MICROSCÓPIO ÓPTICO. As microcápsulas foram formadas conforme descrito no item 4.1 de Material e Métodos. As concentrações crescentes de óleo foram: $1-0 \%$; 2, 3 e $4-1 \%$; 5 , 6 e $7-2 \%$; 8 , 9 e 10 $-3 \%$; 11 , 12 e $13-4 \%$; 14, 15 e $16-5 \%$; 17, 18 e $19-7 \%$; 20, 21 e $22-9 \%$; 23, 24 e $25-12$; 26, 27 e $28-15 \%$; 29,30 e $31-17 \%$; 32 , 33 e $34-20 \%$. Todas as fotografias foram retiradas com aumento de $10 x$ no microscópio óptico, sendo que nas fotos $4,7,10,13,16,19,22,25,28$, 31 e 34 utilizou-se o zoom óptico da máquina digital de aproximadamente $3 x$ para melhor visualização das partículas de óleo. FONTE: O autor (2010)

\subsection{MICROENCAPSULAMENTO DE CÂNFORA E MENTOL}

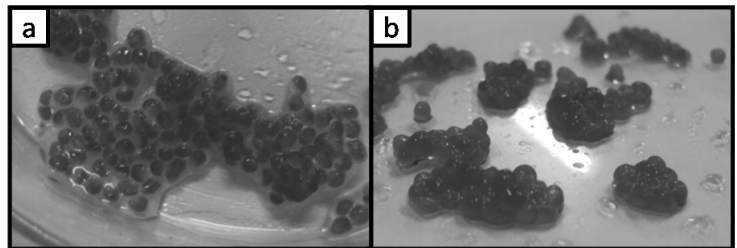

FIGURA 20 - MICROCÁPSULAS DE ALGINATO DE CÁLCIO CONTENDO MENTOL E CÂNFORA, VISÃO AO OLHO NU. As microcápsulas foram formadas conforme descrito no item 4.1.2 de Material e Métodos, pelo uso de alginato de sódio $0,5 \%$ e cloreto de cálcio 1,0\% para formação do material de revestimento e óleo de semente de uva $12 \%$ como veículo formador do núcleo, contendo $0,5 \%$ de ambos os ativos mentol e cânfora. Em a as microcápsulas formadas conforme descrito acima e em $\mathbf{b}$ as microcápsulas formadas conforme variações de agulha e corante também descritas no item 4.1.2.

FONTE: O autor (2010) 


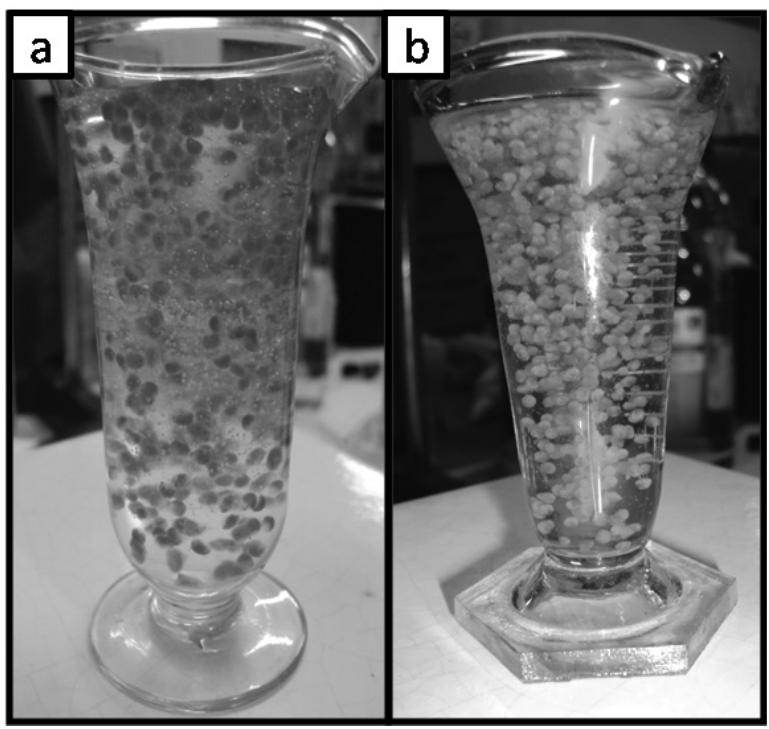

FIGURA 21 - MICROCÁPSULAS DE ALGINATO DE CÁLCIO CONTENDO MENTOL E CÂNFORA INCORPORADAS EM GEL DE NATROSOL. As microcápsulas foram formadas conforme descrito no item 4.1.2 de Material e Métodos, pelo uso de alginato de sódio $0,5 \%$ e cloreto de cálcio 1,0\% para formação do material de revestimento e óleo de semente de uva $12 \%$ como veículo formador do núcleo contendo $0,5 \%$ de ambos os ativos mentol e cânfora. Em a as microcápsulas formadas conforme descrito acima e em $\mathbf{b}$ as microcápsulas formadas conforme variações de agulha e corante também descritas no item 4.1.2. Em ambas as imagens as partículas foram incorporadas na porcentagem de $10 \%$ em gel de natrosol $1 \%$.

FONTE: O autor (2010)

\section{DISCUSSÃO}

\subsection{CAPACIDADE DE MICROENCAPSULAMENTO}

Durante a realização desse estudo, alguns fatores foram apontados como capazes de influenciar o sensorial e aspecto das micropartículas formadas, como: quantidade de óleo encapsulado, tempo de permanência das microcápsulas na solução de alginato de sódio, velocidade de agitação, homogeneidade da mistura de solução de alginato de sódio+óleo vegetal, temperatura da mistura, tempo de lavagem das microcápsulas recém-formadas e concentração de alginato de sódio e cloreto de cálcio.

Observando as microcápsulas a olho nu nas diferentes concentrações de alginato de sódio e cloreto de cálcio, figuras 12, 14, 16 e 18, percebeu-se que a utilização de $0,5 \%$ de ambos os reagentes resultou em microcápsulas de aparência menos homogênea que as demais. No sensorial isso também ficou visível, onde apesar delas estourarem muito mais rapidamente quando pressionadas pelas mãos do que as demais transmitiam uma sensação desagradável pela forma e falta de estrutura. Além disso, durante a formação dessas micropartículas, observou-se que, ao gotejar a solução de alginato de sódio+óleo na solução de cloreto de cálcio, as mesmas já se mostravam deformadas, pela baixa concentração dos reagentes.

Entretanto, com o aumento na concentração, pôde-se observar que as microcápsulas formadas apresentaram-se mais uniformes e arredondadas, além de estarem mais brilhantes e atraentes. Quanto ao sensorial, as mesmas ainda estouravam 
com facilidade nas mãos, o que é desejável a nível dermatológico.

A partir da utilização de $1,0 \%$ de cloreto de cálcio com $0,5 \%$ de alginato de sódio e $0,5 \%$ de cloreto de cálcio com $1 \%$ de alginato de sódio, já se observou a formação de melhores estruturas que ainda mantinham a capacidade de resistirem ao estímulo mecânico. Já o uso de $1 \%$ de ambos os reagentes resultou em maior resistência da parede das partículas.

Em relação à capacidade de encapsulamento, a maior parte das concentrações testadas suportou até $20 \%$ de óleo, com exceção das microcápsulas formadas por $0,5 \%$ de alginato de sódio e cloreto de cálcio, onde o máximo foi $12 \%$ de óleo microencapsulado. Nesse caso, quando da tentativa de encapsular $15 \%$ de óleo, as micropartículas não se formavam, sendo possível observar a presença de óleo na superfície da solução de cloreto de cálcio.

Quanto ao tempo de permanência das microcápsulas na solução de cloreto de cálcio, esse era diretamente proporcional a espessura da parede, ou seja, quanto maior o tempo na solução, mais espessa se mostrou a parede das microcápsulas. Isso acorda com Calero et al. (2008) que notou a liberação mais elevada de diclofenaco de alguns lotes de microcápsulas gastroresistentes contendo esse ativo do que outros lotes devido à espessura da camada protetora da microcápsula.

Já a concentração de óleo apresentou um efeito inverso de proporcionalidade, isto é, quanto maior a concentração de óleo microencapsulado, menor a espessura e resistência das partículas.

Durante o preparo da solução de alginato de sódio+óleo, visto que o óleo não se dissolve na solução de alginato de sódio, permanece apenas disperso, e não se fez uso de um tensoativo, era necessária uma alta agitação para atingir maior homogeneidade da mistura. Vários estudos referentes à velocidade de agitação foram realizados, pelo uso de agitadores magnéticos, de haste/hélice, gral+pistilo+força mecânica, entre outros. O escolhido foi o Ultra-Turrax pelo seu alto poder de agitação da mistura, deixando-a mais estável em relação ao tempo.

Assim, a velocidade de agitação tornou-se um importante fator, bem como a temperatura da mistura, pois a temperatura mais elevada a homogeneização do óleo é facilitada, deixando a mistura mais estável em relação ao tempo. Apesar disso, é possível observar em todas as fotografias a presença de regiões mais concentradas de óleo vegetal nas microcápsulas.

Depois de formadas, as microcápsulas foram lavadas em água deionizada. Se lavadas por pouco tempo, após um período as mesmas encontravam-se mais endurecidas que quando recém-formadas, devido a presença residual do sal cloreto de cálcio, que continuava o processo de formação de alginato de cálcio.

\subsection{MICROENCAPSULAMENTO DE CÂNFORA E MENTOL}

A técnica de microencapsulamento apresentada pode ser utilizada em várias áreas farmacêuticas a fim de aumentar a estabilidade de uma droga ou ainda modificar ou retardar sua liberação em locais específicos de ação. Alguns exemplos incluem a farmacoterapia, pela microencapsulamento de substâncias antiinflamatórias que podem ter seu tempo de atuação no plasma sanguíneo aumentado, prolongando seu 
efeito no organismo; área alimentícia, pela microencapsulamento de óleos essenciais para prevenir a oxidação e a perda de substâncias voláteis e controlar a liberação do aroma; ou ainda aromas, temperos, acidulantes, vitaminas e minerais que alteram a textura, melhoram a qualidade nutricional, aumentam a vida de prateleira ou controlam propriedades dos alimentos processados; para mascarar sabores e cores; no setor agropecuário, na produção de pesticidas, o que reduz a toxicidade ao homem durante o manuseio do mesmo bem como ao ambiente, pois controla a liberação do ativo, reduzindo concentrações elevadas na lavoura e conseguinte a contaminação ambiental (RÊ, 2000).

Assim, realizou-se a incorporação de mentol e cânfora em microcápsulas de alginato de cálcio para fins terapêuticos. As figuras 20 e 21 demonstram a incorporação desses ativos em microcápsulas e a utilização dessas em forma farmacêutica de uso tópico. Visto que esses ativos são muito utilizados pela medicina no tratamento de dores, a forma farmacêutica apresentada tem por objetivo a massagem nos locais afetados para a liberação dos ativos e conseguinte absorção e efeito dos mesmos. A seleção das concentrações desses princípios ativos foi realizada conforme descrito na literatura científica (item 2.3 de Revisão Bibliográfica).

A utilização do corante durante toda a realização desse trabalho foi feita para melhor visualização das microcápsulas. Vale lembrar que o mesmo pode ou não ser utilizado nas formas farmacêuticas.

Próximos estudos podem ser realizados a fim de aprimorar a técnica, pelo uso de um tensoativo junto à solução de alginato + óleo para melhorar a homogeneidade de conteúdo e ainda o desenvolvimento de novas formas farmacêuticas contendo essas microcápsulas como pomadas, cremes, óleos para massagem e produtos para pele seca com sensorial diferenciado (COSTA et al., 2004).

A técnica desenvolvida ainda pode ser utilizada na encapsulamento de outros materiais como, por exemplo, o talco micronizado, caracterizando uma inovação cosmética; outros ativos de ação farmacêutica ou cosmética; ou ainda na área alimentícia, na incorporação de aromas e corantes, melhorando a aceitabilidade ou gerando um diferencial a produtos.

\section{CONCLUSÃO}

A tecnologia de microencapsulamento é capaz de isolar a substância ativa (gotículas líquidas ou partículas sólidas) evitando os efeitos de sua exposição inadequada e ainda desenvolver produtos diferenciados com novas propriedades funcionais e inteligentes (RÊ, 2000).

Assim, o estudo realizado nesse trabalho foi de grande valia, pois fez uso de uma técnica de baixo custo, fácil, passível de ser utilizada na encapsulamento de ativos termolábeis conforme citado no item 2.4.7, de Revisão Bibliográfica, e que faz uso de um polímero biodegradável, não agredindo ao meio ambiente. Além disso, as melhores concentrações de trabalho foram localizadas, quando se trata de aplicação dérmica de ativos, podendo ser base para outros estudos futuros.

A aplicação farmacêutica ou cosmética das microcápsulas de mentol e cânfora apresenta como principal vantagem a proteção desses ativos voláteis, bem como um 
diferencial para atrair o público pela ausência do odor característico desses ativos, o qual é sentido apenas no momento da aplicação.

\section{REFERÊNCIAS}

CALERO, J.; SANCHEZ, Y. F.; TORREZ, R.; HEMANN, E.; LOPEZ, K. Elaboración y caracterización de microcápsulas gastrorresistentes de diclofenac obtenidas por gelificación iónica. Universitas, v. 1 , n. 2, p. 27-30, 2008.

Camphor. Wikipédia: the free encyclopedia. Disponível em: < http://en.wikipedia.org/wiki/Camphor>. Acesso em: 15 mai. 2010.

Cânfora. Laboratórios Catarinense S.A. Disponível em: < http://www.labcat.com.br/index.php/go/ produtos/cod/148>. Acesso em: 15 mai. 2010.

Cânfora. Oswaldo Cruz, 2003. Disponível em: < http://www.oswaldocruz.br/download/fichas/ C\%C3\%A2nfora\%20sint\%C3\%A9tica2003.pdf>. Acesso em: 15 mai. 2010.

CORREA, R. M.; PRATA, A. S.; GROSSO, C. Caracterização de microcápsulas contendo caseína e gordura vegetal hidrogenada obtidas por gelificação iônica. Braz. J. Food Technol., v. 8, n. 1, p. 7380, jan/mar 2005.

COSTA, C.K.; OLIVEIRA, B.; ZANIN, S.M.W.; MIGUEL, M.D. Um estudo da pele seca: produtos emulsionados para seu tratamento e busca de sensorial agradável para o uso contínuo. Visão Acadêmica, v.5, n.2, jul/dez 2004.

DURÁN, N.; AZEVEDO, M. M. Rede de pesquisa em nanobiotecnologia. Nanociência e Nanotecnologia, 2002. Disponível em: <http://www.comciencia.br/reportagens/nanotecnologia/ nano20.htm>. Acesso em 02 jul. 2008.

RÊ, M. I. Microencapsulação em busca de produtos 'inteligentes'. Ciência Hoje - Revista de divulgação científica da sociedade brasileira para o progresso a ciência, São Paulo, v. 27, n. 162, p. 24-29, jul. 2000.

ROWE, R. C.; SHESKEY, P. J.; QUINN, M. E. Handbook of pharmaceutical Excipients. $6^{\text {th }}$. ed. London: Pharmaceutical Press, 2009.

SILVA, C.; RIBEIRO, A.; FERREIRA, D.; VEIGA, F. Administração oral de peptídeos e proteínas: II. Aplicação de métodos de microencapsulação. Revista Brasileira de Ciências Farmacêuticas, v. 39, n. 1, jan/mar 2003. 